\title{
APRESENTAÇÃO DO PRIMEIRO CASO AUTOCTONE DE DOENÇA DE CHAGAS DIAGNOSTICADO NO ESTADO DE SANTA CATARINA, BRASIL
}

\author{
Osvaldo Vitorino OLIVEIRA (1) \\ Fernando Osvaldo OLIVEIRA (2) \\ Joaquin A. FERREIRA NETO (s)
}

\begin{abstract}
Oliveira, O. V.; Oliveira, F. O. \& Ferreira Neto, J. A. - Apresentação do primeiro caso autóctone de doença de Chagas diagnosticado no Estado de Santa Catarina, Brasil. Rev. Saride puibl., S. Paulo, 4:211-14, dez. 1970.

Resumo - Apresentação do primeiro caso de doença de Chagas, diagnosticado no município de Gaspar, Estado de Santa Catarina, Brasil. Como năo se conseguiu demonstrar a presença de triatomíneos na região, não foi possível determinar especificamente o mecanismo de transmissão.
\end{abstract}

\section{INTRODUCAO}

Até agora, são poucos os trabalhos publicados sôbre a pesquisa da doença de Chagas em Santa Catarina, talvez, devido a ausência de casos clínicos da doença. Trabalhos de pesquisa em campo encon. tramos muito poucos e, nenhum, explicando o encontro de triatomíneos domicilia. res o que, elucida o fato da inexistência de casos clínicos. Leal, Ferreira Neto \& Martins ${ }^{7}$ e Galvão et al. ${ }^{6}$ são os únicos autores, de que temos conhecimento, que publicaram trabalhos sôbre triatomíneos silvestres e peridomiciliares. LEAL et al. ${ }^{7}$, explicam que na ilha de Santa $\mathrm{Ca}$. tarina, o Panstrongylus megistus tem hábitos quase que exclusivamente silvestres sendo muito raro o seu encontro no domi. cílio e, classificam a doença de Chagas como um evento de muita baixa probabilidade, porém, de possível ocorrência. Nesse mesmo trabalho relatam o achado de um caso sorológico positivo, em inquérito realizado na ilha de Santa Catarina. O Rhodnius domesticus também, muito raramente, é encontrado no domicílio.

Até o presente momento foram registra. dos os seguintes triatomíneos no Estado de Santa Catarina:
a) Panstrongylus megistus. 1, 4, 5, 7
b) Rhodnius domesticus. 4, 5, 6, ?
c) Triatoma sordida."
d) Triatoma infestans."

Frecebido para publicação em 24-9-1970.

(1) Aluno do curso de Pós-Graduaçăo em Saúde Pública para Médicos da Faculdade de Pública da USP - Sáo Paulo, SP, Brasil.

(2) Da Cadeira de Higiene e Medicina Preventiva da Faculdade de Medicina da Universidae Federal de Santa Catarina - Florinópolis, SC, Brasil.

(3) Da Campanha de Erradicação da Malária do Ministério da Saúde - Florianópolis, S.C.; Brasil. 
OLIVEIRA, O. V.; OLIVEIRA, F. O. \& FERREIRA NETO, J. A. - Apresentacão do primelro caso autóctone de doenca de Chagas diagnosticado no Estado de Santa Catarina, Brasil. Rev. Saúde puibl., S. Paulo, 4:211-14, dez. 1970.

0 Triatoma infestans de Santa Catarina segundo dados do inquérito realizado pelo Departamento Nacional de Endemias Ru. rais (DNERu) ${ }^{(1)}$ nos anos de 1954 a 1957 , só foi encontrado intradomiciliarmente em alguns municípios do extremo oeste. Essa área é semelhante a do noroeste do Estado do Rio Grande do Sul, onde o inseto é fre. qüente e onde existem muitos casos da doença. Todavia, nesse mesmo inquérito em 1957, o triatomíneo não foi encontra. do na região do Vale do Itajaí, local onde foi diagnosticado o presente caso de infecção.

\section{MATERIAL E METODOS}

J.C.S., 6 anos, natural de Blumenau, Santa Catarina, apresentou-se em meados de maio, relatando queda acidental de altura aproximadamente de $60 \mathrm{~cm}$ com contusão na região lombar. Além disso, apresentava miíase na região temporal esquerda e alteração local caracterizada por edema bipalpebral bilateral, mais acentuada do lado esquerdo. Essa sintomatologia, após alguns dias, generalizou-se com febre, astenia, anorexia, dor lombar e oligúria. Com êste quadro clínico, foi internado e submetido a terapêutica para síndrome nefrótico, além de analgésicos, tipo ácido acetilsalicílico. Com a redução do edema da parede abdominal, evidenciou-se discreta hepato e esplenomegalia. Segundo informaçốes verbais dos pediatras que atenderam o paciente, o mesmo apresentou hemograma que tinha apenas ligeira linfocitose e um parcial de urina dentro dos limites da normalidade. Desde o início do quadro revelava taquicardia moderada, aproximadamente 100 b.p.m. Como o paciente apresentava picos febrís, e por tratar-se de zona malarígena, foi solicitada hemoscopia para protozoários. Esta, à gôta espêssa e após coloração pelo Giemsa, foram evidenciados tripanosomas.
Foi realizado xenodiagnóstico com 10 ninfas em $4 .^{\circ}$ e $5 .^{\circ}$ estágio de Rhodnius prolixus e Triatoma infestans, aplicados na face anterior das coxas do paciente. 0 conteúdo foi examinado aos 15,30 e 45 dias, mostrando-se sempre negativo.

Foram realizadas provas sorológicas de imunofluorescência (1:1024) e Machado Guerreiro $(3,2)$ cujos títulos não deixam margem a dúvidas quanto à etiologia da doença.

O xenodiagnóstico e as provas sorológicas foram realizadas com aproximadamente 45 dias de doença e, a hemoscopia revelativa, com 15 dias após o início do quadro.

\section{DISCUSS A}

Conforme foi demonstrado, não há dú. vidas de que o caso relatado trata-se de Doença de Chagas. 0 que não foi expli. cado, entretanto, é como foi adquirida a infeç̧ão.

$O$ caso foi notificado às autoridades sa. nitárias locais que procuraram elucidar o mecanismo de transmissão e avaliar o risco que isso poderia acarretar à Saúde Pública. Tentaram obter, das pessoas residentes na área, informaçōes sôbre "barbeiros". 0 não encontro dêsse hemipteros no domicílio e peridomicílio e a ignorância por parte dos habitantes quanto aos mesmos, levaram-nos a considerar a não existência de triatomíneos domiciliares na região.

Algumas semanas mais tarde, realizamos "pirização" da residência e abrigos de animais domésticos, também nada encontran. do.

O município de Gaspar faz parte da zona fisiográfica da Bacia do Itajaí. Está situada a $26 .^{\circ}, 55^{\prime}, 15^{\prime \prime}$ de latitude sul; $48^{\circ}$, $57^{\prime}, 02^{\prime \prime}$, de longitude $W ; 7$ metros acima do nível do mar, com temperatura mé- 
OLIVEIRA, O. V.; OLIVEIRA, F. O. \& FERREIRA NETO, J. A. - Apresentaçăo do primetro caso autóctone de doença de Chagas diagnosticado no Estado de Santa Catarina, Brastl. Rev. Saúde puibl., S. Paulo, 4:211-14, dez. 1970.

dia de $23^{\circ} \mathrm{C}$, e aproximadamente $393 \mathrm{~km}^{2}$ de área.

0 local estudado compõe-se de uma casa residencial, em alvenaria nas paredes ex. ternas e madeira nas paredes internas, ainda em bom estado de conservação mas, com locais que podem servir de esconderijo a triatomíneos. Observa-se a presença de anexos constituídos por galinheiro, chiqueiro, além de um rancho com um pequeno alambique. A fossa é externa e também com possibilidade de abrigo a triatomíneos. Com exceção da parte em frente, as construções são rodeadas por vegetação florestal.

Quanto ao mecanismo de transmissão da doença, aventuramo-nos a apresentar al. gumas hipóteses.

Sabemos da existência de triatomíneos silvestres pois, a região é climàticamente semelhante a da ilha de Santa Catarina, com a mesma fauna e, dêste modo, deverá ter também os mesmos triatomíneos. Par. tindo desta premissa, sugerimos as seguin. tes hipóteses de transmissão:

a) possibilidade de que um triatomí. neo silvestre tenha vindo ao domicílio, atraído pela luz ou por estar faminto, e, dêste modo, picado o paciente.

b) possibilidade de migração de triatomíneos domiciliares que, com a melhoria das vias de comunicações, tenham vindo do oeste. Esta hipótese talvez seja possível devido ao fato de que o Triatoma infestans não é encontrado neste tipo de cli. $\mathrm{ma}^{2}$ e por condiçōes adversas tenha morrỉo, não se colonizando.

c) possibilidade de transmissão oral.

d) possibilidade de outro mecanismo, ainda ignorado. A concomitância com mí́ase poderia não ser sòmente coinci. dência (?).

O paciente nunca recebeu transfusão san. guínea de modo que a hipótese dêsse meio de transmissão fica afastada.

\section{CONCLUSAO}

Como o paciente nunca saiu da região e encontramos tripanosomas no sangue periférico, concluímos ser o caso positivo para Doença de Chagas, incluindo Santa Catarina na relação dos Estados em que a doença foi diagnosticada. Devido a exigüidade de recursos, não nos foi possível realizar um inquérito sorológico na região e, assim determinar a amplitude da infecção humana.

Olileira, O. V.; OLIVEIra, F. O. \& FerretRA NETO, J. A. [The first autochthonous case of Chagas' disease in the State of Santa Catarina, Brazil]. Rev. Saúde públ., S. Paulo, 4:211-14, dez. 1970.

Summary - The first case of Chagas' diseases was diagnosed in Santa Catarina, Brazil. As it was not possible to find the triatominae bugs in that region, the mechanism of transmission remained obscure.

\section{A GRADECIMENTOS}

Ao Dr. Edmundo Juarez, pela orientação recebida; ao Departamento de Parasi. tologia da Faculdade de Medicina da USP pela realização dos exames complementares; aos Drs. Rodolfo Schwab, João Spengler e Fernando Schwancke, as informaçōes recebidas.

\section{REFERENCIAS BIBLIOGRAFICAS}

1. ARAGAO, M. B. - Aspectos climáticos da Doenca de Chagas. Area de ocorrencia do P. megistus. Rev. bras. Malar., 18:171-93, jul./dez. 1961.

2. ARAGAO, M. B. \& DIAS, E. - Aspectos climáticos da Doenca de Chagas. Considerações sôbre a distribulção geográfica do Triatoma infestans. Rev. bras. Malar, 8: 633-41, out. 1956.

3. BUSTAMANTE, F. M. de - Distribuição geografica dos transmissores da Doenca de Chagas no Brasil e sua relação com certos fatôres climáticos. Epidemiologia e e profilaxia da enfermidade. Rev. bras. Malar., 9:191-211, abr. 1967. 
OLIVEIRA, O. V.; OLIVEIrA, F. O. \& FERREIRA NETO, J. A. -Apresentacão do primeiro caso autóctone de doenca de Chagas diagnosticado no Estado de Santa Catarina, Brasil. Rev. gas. Arq. Hig., S. Paulo, 27s317-30, dez.

4. CORREA, R. R. - Informe sobre a doenca de Chagas no Brasil e, em especial no Estado de Săo Paulo. Rev. bras. Malar., 20: 39-81, jan./Jun. 1968.

5. COUTINHO, J. de O. - Contribuiçăo ao estudo da epldemiologia da Doenca de Chagas. Arq. Hig., S. Paulo, 27:317-30, dez. 1962.
6. GalvaO, A. B. et al. - sobre a distribulcão geográfica e infecçáo natural do Rhodnius domesticus. Rev, bras. Malar, 13: 57-60, Jan./jun. 1961.

7. LEAL, H.; FERREIRA NETO, J. A. \& MARTINS, C. M. - Dados ecológicos sôbre triatomineos silvestres da Ilha de Santa Catarina (Brasil). Rev. Inst. Med. trop S. Paulo, s:213-20, set./out. 1961. 